\title{
First Report on the Volatile Composition of Tricholoma anatolicum in Comparison with Tricholoma caligatum
}

\author{
Hatıra Taşkın $\oplus^{1 *}$, Zeynep Dilan Çelik $\oplus^{2}$, Fuat Bozok $\oplus^{3}$, \\ Turgut Cabaroğlu ${ }^{2}$ and Saadet Büyükalaca ${ }^{1} 1$
}

\author{
${ }^{1}$ Department of Horticulture, Faculty of Agriculture, Cukurova University, 01330 Adana, \\ Türkiye \\ ${ }^{2}$ Department of Food Engineering, Faculty of Agriculture, Cukurova University, 01330 \\ Adana, Türkiye \\ ${ }^{3}$ Department of Biology, Faculty of Art and Sciences, Osmaniye Korkut Ata University, 80000 \\ Osmaniye, Türkiye
}

(Received December 07, 2018; Revised March 12, 2019; Accepted March 18, 2019)

\begin{abstract}
Tricholoma anatolicum collected from Turkey is consumed by public and exported to Japan every year. It was previously identified as Tricholoma caligatum until it was recognized as a new species. In the existing literature, there is no information on the aromatic composition of T. anatolicum. Therefore, in this study it was aimed to identify the volatile composition of $T$. anatolicum together with $T$. caligatum. Species identification was confirmed using molecular analyses based on ITS rDNA sequencing. Volatile compounds of both mushroom species were extracted using liquid-liquid extraction method and determined by Gas Chromatography-Mass Spectrometry-Flame Ionization Detector (GC-MS-FID). In the two Tricholoma species, 31 volatiles were obtained and grouped in seven chemical classes. The amounts of alcohols, volatile acids and esters were found to be higher in T. anatolicum, whereas the amounts of terpenes were detected as higher in $T$. caligatum. 1-Octen-3-ol responsible for the mushroom-like odour was only found in T. anatolicum.
\end{abstract}

Keywords: Tricholoma anatolicum; Tricholoma caligatum; Tricholomataceae; volatile; aroma composition; Turkey. () 2019 ACG Publications. All rights reserved.

\section{Introduction}

The genus Tricholoma encompases large number of mycorrhizal species and some of them are prized commercially, particularly Tricholoma matsutake and Tricholoma anatolicum. The latter species is known as "Cedar Mushroom" in Turkey due to its ectomycorrhizal relationship with Cedrus libani. This peculiar species was discovered and described in details by Turkish researchers $[1,2]$. The main differences of this Anatolian species from other members of Tricholoma are its host preference and its odour and aroma reminding the one of its host tree. This mushroom species is also colloquially

\footnotetext{
*Corresponding author: E-Mail: hatirataskin1@gmail.com; Phone: 00903223386388 Fax: 00903223386388
} 
known in Turkey as "Katran Mantarı" (i. e. tar mushroom) due to its odour comes from Cedar tree [2]. Most of the other Tricholoma species form ectomycorrhizal relationship with Pinus spp. and are therefore known as "Pine Mushroom". For example, T. matsutake, claimed as the most valuable Tricholoma species, has ectomycorrhizal relationship with Pinus densiflora. Cedrus libani named as "Taurus Cedar" in Turkey has a plump trunk, thick branches,-splendid structure and may reach $40 \mathrm{~m}$ in height. The pyramidal top in young trees spreads with ages and is shaped like an umbrella. It has used for different purposes from the ancient Egyptian, Phoenicians and Assyrians to day due to its highly valuable essential oil and its fragrant wood. Distribution of Taurus Cedar in Turkey has begins from Köyceğiz and Fethiye province of West Mediterranean and reaches in the Kahramanmaraş province of the East Mediterranean. This broad distribution area is situated between the $28^{\circ}-37^{\circ}$ east longitudes and the $36^{\circ} 20^{\prime}-38^{\circ} 40^{\prime}$ northern latitudes. The altitude is $1000-2200 \mathrm{~m}$ in the Mediterranean Region, 670-920 m in Niksar location of North and 800-1250 m in Erbaa location [39]. In accordance with the distribution of cedar forests in Turkey, T. anatolicum occurs in cedar forests about 30 years old on well-drained, sandy and non-fertile soil in areas with Mediterranean climate at 1400-1700 m elevation between October and November [2,10]. The commercial importance and value of this species for the Turkish public was discussed in details in a book chapter written by Turkish scientists [11].

Mushrooms have been consumed as food or used as food-flavouring material since ancient times because of their unique flavour. The typical flavour substances of mushrooms can be classified into non-volatile components and volatile compounds. Among these compounds, the aliphatic alcohols and ketones with eight carbon atoms (1-octen-3-ol, 2-octen-1-ol, 3-octanol, 1-octanol, 1-octen-3-one, 3 -octanone) are in charge-for the mushroom-like flavour. The volatile composition of mushrooms can be affected by several factors, such as species, the part of mushroom used, maturity of mushroom and the substrate composition for mushroom species cultured or habitat for uncultured mushroom species [12]. Although mushrooms are consumed extensively, the studies on their aroma compositions have been limited.

T. anatolicum was known as T. caligatum in Turkey until being proposed as a new species by Turkish and Italian mycologists [1]. The differences between those two species were outlined in details in a study carried out by Turkish scientists [2]. While $T$. caligatum has strong and similar to Inocybe corydalina odour, sweetish-bitter to bitter taste and tends to form mycorrhiza with hardwoods or pine trees, $T$. anatolicum has fragrant and similar to $C$. libani odour, very mild, pleasant taste and is in mycorrhizal relationship with $C$. libani. Additionally, there are many morphological differences between those species concerning details as colour, pileus, stipe, spore and hyphae. Aroma composition of some Tricholoma species has been assessed until today by different researchers, who tackled T. matsutake [13, 14], T. equestre [15], T. ustaloides, T. sulphureum [16], and T. terreum [17]. The chemical composition of T. anatolicum was also determined by two different research groups from Turkey $[18,19]$. However, no study has been conducted so far to investigate the aromatic composition of $T$. anatolicum. Therefore, the focus of this study was to determine aroma compounds of $T$. anatolicum in comparison with T. caligatum.

\section{Materials and Methods}

\subsection{Fungi Materials}

Fresh Tricholoma species were used as material for aromatic studies in this study. While $T$.

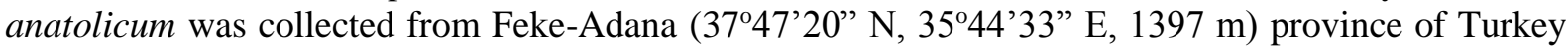
under C. libani, T. caligatum was obtained from Pozant1-Adana $\left(37^{\circ} 25^{\prime} 24^{\prime \prime}\right.$ N, $34^{\circ} 52^{\prime} 45^{\prime \prime}$ E, $\left.850 \mathrm{~m}\right)$ province of Turkey under Pinus brutia (Figure S1). Dried samples were used for molecular analyses including DNA isolation and sequencing. Voucher specimens have been deposited in the Herbarium of Osmaniye Korkut Ata University, Osmaniye, Turkey (voucher numbers: T. anatolicum - FBozok 00204, T. caligatum - FBozok 00205). 


\subsection{Chemicals}

Dichloromethane ( $\geq 99.9 \%$ purity), sodium sulphate anhydrous $(99 \%)$ and internal standard (4nonanol) were obtained from Merck (Darmstadt, Germany). A mixture of n-alkane standards ranging from $\mathrm{C}_{8}-\mathrm{C}_{40}$ were used for the determination of retention indices and they were provided from Sigma Aldrich (St Louis, MO, USA) (E)-3-penten-ol (96\% purity), limonene (97\% purity), 3-octanone ( $\geq$ 98\% purity), 2-hexanol ( $\geq 98 \%$ purity), 3-methyl-2-buten-1-ol $(\geq 98 \%$ purity), nonanal $(\geq 99.5 \%$ purity), 3-octanol ( $\geq 98 \%$ purity), (E)-2-octenal (97\% purity), (Z)-furan linalool oxide ( $\geq 97 \%$ purity), (E)-limonene oxide (97\% purity), 1-octen-3-ol ( $\geq 98 \%$ purity), linalool ( $\geq 98.5 \%$ purity), $\gamma$ butyrolactone ( $\geq 99 \%$ purity), $2(5 \mathrm{H})$ furanone ( $\geq 98 \%$ purity), (Z)-pyran linalool oxide ( $\geq 97 \%$ purity), 1-phenylethanol ( $\geq 99 \%$ purity), hexanoic acid ( $\geq 99 \%$ puity), (Z)-nerolidol ( $\geq 96 \%$ purity), (E)methyl cinnamate $(\geq 98 \%$ purity), decanoic acid $(\geq 99 \%$ puity), dodecanoic acid ( $\geq 99 \%$ purity), linoleic acid ( $\geq 98.5 \%$ purity), pentadecanoic acid ( $~ 99 \%$ purity), hexadecanoic acid ( $\geq 99 \%$ purity) were obtained from Sigma Aldrich (St Louis, MO, USA). (Z)-2-octen-1-ol (97\% purity) was obtained from Alfa Aesar (Haverhill, USA).

\subsection{Aroma Compounds Analysis}

\subsubsection{Extraction}

Fresh mushroom sample ( $25 \mathrm{~g})$ was homogenized with a mechanic blender and then transferred into a $250 \mathrm{~mL}$ erlenmeyer flask. As internal standard, dichloromethane $(50 \mathrm{~mL})$ and $40 \mu \mathrm{g}$ of 4 nonanol were added into flask and the mixture was stirred at $4^{\circ} \mathrm{C}$ for 30 minutes under nitrogen gas $[14,20]$, then the mixture was centrifuged at $4^{\circ} \mathrm{C}(9000 \mathrm{~g}, 15 \mathrm{~min})$. After all, the organic phase was recovered. Before gas chromatography/mass spectrometry (GC/MS) analysis, the organic extract was dried over sodium sulphate and concentrated to a volume of $0.5 \mathrm{~mL}$ with a Vigreux distillation column $[14,20]$. Each sample was extracted in triplicate. The concentration of volatile compounds were quantified from the flame ionization detection (FID) peaks areas and the internal standard, 4-nonanol. The response factor was set to 1 for all compounds [21].

\subsubsection{GC/MS-FID Analysis}

The volatile compounds were analyzed by using GC/MS-FID. The gas chromatography (GC) system consisted an Agilent 6890 chromatograph equipped with a flame ionization detector (FID) (Wilmington, DE, USA) and an Agilent 5973-Network mass selective detector (MSD). Volatile compounds were separated on DB-Wax $(30 \mathrm{~m}$ length $\times 0.25 \mathrm{~mm}$ i.d. $\times 0.5 \mu \mathrm{m}$ thickness; J\&W Scientific Folsom, CA, USA) column and a total of $3 \mu \mathrm{L}$ sample of extract was injected. Injector and FID detectors were set at $250^{\circ} \mathrm{C}$ and flow rate of carrier gas (helium) was $1.5 \mathrm{~mL} / \mathrm{min}$. The oven temperature of the DB-Wax column was increased from $40^{\circ} \mathrm{C}$ (after 3 min holding) to $90^{\circ} \mathrm{C}$ at a rate of $2^{\circ} \mathrm{C} / \mathrm{min}$, then at a rate of $3^{\circ} \mathrm{C} / \mathrm{min}$ to $130^{\circ} \mathrm{C}$, and at a rate of $4^{\circ} \mathrm{C} / \mathrm{min}$ to $240^{\circ} \mathrm{C}$ with a final hold at $240^{\circ} \mathrm{C}$ for $12 \mathrm{~min}$. For the mass selective detector, the same oven temperature programs were used. MS scan conditions as follows: source temperature $120^{\circ} \mathrm{C}$, interface temperature $250^{\circ} \mathrm{C}$, EI energy 70 $\mathrm{eV}$, mass scan range 29-350 a.m.u and a scan rate $1.0 \mathrm{scan} / \mathrm{s}$. Volatile compounds were identified by retention indices (RI), mass spectral database (Wiley 6, NIST 98). Identification of some volatile compounds was confirmed by the injection of their chemical standard into GC-MS system. Retention indices of the volatile compounds were calculated by using an n-alkane series $\left(\mathrm{C}_{8}-\mathrm{C}_{22}\right)[14,20]$.

\subsection{Statistical Analysis}

The independent-samples analysis of variance tests ( $t$-test) were carried out to compare the significant differences of the mean values of the volatile compounds with $p<0.05$. SPSS Statistics software version 20.0 (Chicago, IL, USA) was used for statistical analysis. 


\subsection{Molecular Analyses}

Species names of the Tricholoma samples collected were confirmed by obtaining DNA sequences of ITS rDNA gene region amplified using ITS1F and ITS 4 primers [22] and then by comparing with sequences in Genbank database. Eurx genematrix universal DNA purification kit was used to isolate DNA from dried samples. PCR conditions were set up as follows: $95^{\circ} \mathrm{C}$ for $5 \mathrm{~min}$ and $30 \mathrm{~s}$ at $9{ }^{\circ} \mathrm{C}, 60 \mathrm{~s}$ at $54^{\circ} \mathrm{C}, 90 \mathrm{~s}$ at $72^{\circ} \mathrm{C}$ by 30 cycles and final extension $72^{\circ} \mathrm{C}$ for $5 \mathrm{~min}$. PCR amplifications were verified by electrophoresis on $1.5 \%$ agarose gel and then DNA sequence analyses of successful amplifications were performed by BigDye Terminator v3.1 Sequencing Kit using ITS1F-ITS4 primers. Sequencing reactions were run on ABI 3730XL Sanger sequencer (Applied Biosystems, Foster City, CA, US) and then Sequencher version 5.4.5 (Gene Codes, Ann Arbor, MI, USA) was used for editing and aligning of raw sequence chromatograms. The sequences obtained from this study were deposited in GenBank with MH170219 and MH173092 accession numbers.

\section{Results and Discussion}

The volatile compound analysis of two Tricholoma species was carried out using GC-MS/FID and compounds identified were shown in Table 1 . A total of 31 volatile compounds including 8 alcohols $(1,4,5,7,11,13,15,18), 4$ aldehydes and ketones $(3,6,8,16), 7$ terpenes $(2,9,10,12,17$, 20, 25), 1 ester (21), 9 volatile acids $(19,22,23,24,27,28,29,30,31)$ and 1 lactone (14), 1 indole derivative compound (26) were identified (identification numbers correspond to those reported in Table 1 and are presented in supporting information as Figure S2 and Figure S3). Two different Tricholoma species showed different volatile profiles. In the $T$. anatolicum (25) was identified the higher number of volatiles than the T. caligatum (15). In T. anatolicum, 1-octen-3-ol was detected as the most abundant compound (46\%), followed by methyl cinnamate (30.2\%), linoleic acid (10.6\%) and (E)-2-octen-1-ol (5.1\%). In contrast, 2,5-dimethyl, 1-H-indole (41.5\%) known as indole derivatives compound was the most dominant component in the T. caligatum and it was followed by methyl cinnamate $(39 \%)$.

As seen in Table 1, among alcohols, 1-octen-3-ol known as eight carbons (C8) derivate was found to be major volatile compound in T. anatolicum. This component was also reported as the most abundant aroma compound in other Tricholoma species, especially in T. matsutake in the previous studies [34, 35]. Aroma threshold value of 1-octen-3-ol is $200 \mu \mathrm{g} / \mathrm{kg}$ [36] and it is an important component due to its low perception threshold value and its specific sensory characteristic. The concentration of 1-octen-3-ol extremely exceeds its threshold value in T. anatolicum, whereas it could not be detected in T. caligatum. Same result was obtained from a study carried out by French group on T. caligatum [37]. In a study performed on T. terreum and T. fractium, 1-octen-3-ol compound commonly found in Tricholoma species could not be detected [12]. The major component 1-octen-3-ol possesses a mushroom-like aroma and is known as 'mushroom alcohol'. It has been reported that this compound is derived from linoleic acid through oxygenation of the fatty acid and subsequent cleavage of the fatty acid hydroperoxide. However, the precise pathway to 1-octen-3-ol in mushrooms has not been fully elucidated [38, 39]. A research group [38] reported that 1-octen-3-ol formation may be limited by either competitive product inhibition [13-hydroxyperoxydes (13-HPOD)] or low substrate availability due to lipophilic interaction of the fatty acid substrate with the crude mycelium homogenate. In our study, the absence of 1-octen-3-ol in T. caligatum may be due to lack of linoleic acid or formation of 13-HPOD. (E)-2 Octen-1-ol was the second most abundant C8 derivatives compound and it was only found in T. anatolicum. The other C8 derivatives compounds; 3-octanol and 1-octanol were at lower content. It is generally accepted that $\mathrm{C} 8$ compounds are the major volatiles contributing to mushroom, mushroom-like/buttery, mushroom-like/chemical flavour [14, 40, 41]. The presence and concentration of these compounds depend on, genera, species, strains, maturity and geographical origin of the mushroom [34, 42]. Five other alcohols; (E) 3-penten-2-ol, 2-hexenol, 2-methyl-2-buten-1-ol, and 1-phenylethanol were also identified with lower content. In addition, 1phenylethanol was only detected in T. anatolicum.

3-Octanone is one of the important C8 aliphatic compounds and it was the most abundant ketone in T. anatolicum, but it was not identified in T. caligatum. Aroma threshold value of 3- 
octanone is $500 \mu \mathrm{g} / \mathrm{kg}$ [36] and it has mushroom-like-buttery notes [13]. However, it was found under its threshold value in T. anatolicum. 3-Octanone was found to be most abundant ketone in six different mushroom species in a previous study conducted by Portuguese scientists [12]. On the other hand, this compound was not detected in a study carried out by another Portuguese group which are worked with eleven different mushroom species [15]. Two aldehydes; nonenal and 2-octenal were only identified in T. anatolicum at very low content.

Table 1. Volatile composition of T. anatolicum and T. caligatum $(\mu \mathrm{g} / \mathrm{kg})$

\begin{tabular}{|c|c|c|c|c|c|c|c|}
\hline Peak no & LRI & RI & Volatile Compounds ( $\mu \mathrm{g} / \mathrm{kg})$ & T. anatolicum & T. caligatum & Sig. & ID \\
\hline 1 & $1177^{\mathrm{d}}$ & 1179 & (E)-3-Penten-2-ol & $369.8 \pm 24.7$ & $437.4 \pm 5.0$ & $*$ & RI,MS,Std \\
\hline 2 & $1195^{\mathrm{a}}$ & 1190 & Limonene & $63.9 \pm 2.8$ & >LOQ & $*$ & RI,MS,Std \\
\hline 3 & $1261^{\mathrm{e}}$ & 1253 & 3-Octanone & $240.2 \pm 15.5$ & $>$ LOQ & $*$ & RI,MS,Std \\
\hline 4 & $1313^{f}$ & 1310 & 2-Hexanol & $92.7 \pm 4.4$ & $123.3 \pm 2.0$ & $*$ & RI,MS,Std \\
\hline 5 & $1320^{\mathrm{g}}$ & 1315 & 3-Methyl-2-buten-1-ol & $38.3 \pm 5.4$ & $64.2 \pm 1.9$ & $*$ & RI,MS,Std \\
\hline 6 & $1390^{\mathrm{h}}$ & 1397 & Nonanal & $47.9 \pm 3.1$ & $>$ LOQ & $*$ & RI,MS,Std \\
\hline 7 & $1396^{\mathrm{e}}$ & 1394 & 3-Octanol & $62.7 \pm 5.2$ & $143.9 \pm 9.2$ & $*$ & RI,MS,Std \\
\hline 8 & $1437^{\mathrm{e}}$ & 1430 & (E)-2-Octenal & $26.4 \pm 0.7$ & $>$ LOQ & $*$ & RI,MS,Std \\
\hline 9 & $1439^{e}$ & 1439 & (Z)-furan Linalool oxide & >LOQ & $93.9 \pm 1.7$ & $*$ & RI,MS \\
\hline 10 & $1463^{i}$ & 1459 & (E)-Limonene oxide & $>$ LOQ & $62.0 \pm 1.3$ & $*$ & RI,MS \\
\hline 11 & $1451^{b}$ & 1458 & 1-Octen-3-ol & $44289.4 \pm 349.7$ & $>$ LOQ & $*$ & RI,MS,Std \\
\hline 12 & $1540^{\mathrm{h}}$ & 1537 & Linanol & $>$ LOQ & $40.8 \pm 1.4$ & $*$ & RI,MS,Std \\
\hline 13 & $1579^{b}$ & 1579 & 1-Octanol & $869.6 \pm 42.2$ & $11.5 \pm 0.4$ & $*$ & RI,MS,Std \\
\hline 14 & $1635^{c}$ & 1630 & y-Butyrolactone & $62.2 \pm 2.0$ & $>$ LOQ & $*$ & RI,MS,Std \\
\hline 15 & $1620^{b}$ & 1620 & (E)-2-Octen-1-ol & $4985.7 \pm 220.1$ & $>$ LOQ & $*$ & RI,MS,Std \\
\hline 16 & $1767^{\mathrm{h}}$ & 1761 & $2(5 \mathrm{H})$ Furanone & $51.4 \pm 3.3$ & $>$ LOQ & $*$ & RI,MS,Std \\
\hline 17 & $1770^{\mathrm{h}}$ & 1770 & (Z)-pyran Linalool oxide & $>$ LOQ & $25.4 \pm 0.7$ & $*$ & RI,MS \\
\hline 18 & $1788^{j}$ & 1795 & 1-Phenylethanol & $66.8 \pm 4.5$ & $>$ LOQ & $*$ & RI,MS,Std \\
\hline 19 & $1828^{\mathrm{e}}$ & 1830 & Hexanoic acid & $20.9 \pm 1.6$ & $>$ LOQ & $*$ & RI,MS,Std \\
\hline 20 & $2050^{\mathrm{e}}$ & 2041 & (Z)-Nerolidol & $>$ LOQ & $54.0 \pm 0.8$ & $*$ & RI,MS,Std \\
\hline 21 & $2051^{\mathrm{h}}$ & 2048 & Methyl cinnamate & $29074.1 \pm 1193.2$ & $3495.7 \pm 18.2$ & $*$ & RI,MS,Std \\
\hline 22 & $2182^{k}$ & 2182 & 2-Octenoic acid & $40.4 \pm 2.0$ & $>\mathrm{LOQ}$ & $*$ & RI,MS \\
\hline 23 & $2268^{g}$ & 2270 & Decanoic acid & $20.4 \pm 1.3$ & $>$ LOQ & $*$ & RI,MS,Std \\
\hline 24 & $2479^{1}$ & 2474 & Dodecanoic acid & $119.2 \pm 1.0$ & $>$ LOQ & $*$ & RI,MS \\
\hline 25 & $2500^{\mathrm{m}}$ & 2495 & Drimenol & $25.3 \pm 1.2$ & $77.2 \pm 0.8$ & $*$ & RI,MS \\
\hline 26 & - & 2520 & 1-H-indole, 2,5-Dimethyl & $>$ LOQ & $3715.0 \pm 59.6$ & $*$ & RI,MS,std \\
\hline 27 & - & 2544 & Linoleic acid & $10268.3 \pm 341.2$ & $405.8 \pm 69.3$ & $*$ & RI,MS,Std \\
\hline 28 & $2729^{k}$ & 2720 & Pentadecanoic acid & $679.8 \pm 8.9$ & $>\mathrm{LOQ}$ & $*$ & RI,MS,Std \\
\hline 29 & $2882^{\mathrm{m}}$ & 2886 & Hexadecanoic acid & $2721.6 \pm 113.1$ & $190.4 \pm 2.2$ & $*$ & RI,MS,Std \\
\hline 30 & $3136^{n}$ & 3130 & Octadecanoic acid & $303.6 \pm 3.4$ & $>\mathrm{LOQ}$ & $*$ & RI,MS \\
\hline 31 & $3173^{n}$ & 3167 & Oleic acid & $1573.4 \pm 19.6$ & $>$ LOQ & $*$ & RI,MS \\
\hline
\end{tabular}

RI: Retention indices calculated on DB-Wax capillary column; LRI: Literature retention indices on DB-WAX column reported from literature a[13], b[14], c[21], d[23], e[24], f[25], g[26], h[27], i[28], j[29], k[30], 1[31], m[32], n[33]; \pm Standard deviation; ID: Identification; MS: Mass spectrometry; Std: Chemical standard; LOQ: Limit of quantification; Sig.: Significance at which means differ as shown using analysis of variance $* \mathrm{p}<0.05$ level.

Terpenes are important volatile components concerning the volatile composition of mushrooms. While six terpene compounds were found in $T$. caligatum, only two components were detected in T. anatolicum. Limonene was the most abundant terpene compound in T. anatolicum (71.6\%) and it was not recorded in T. caligatum. Different values have been reported on limonene perception threshold value in the literature, which are reported as $10 \mu \mathrm{g} / \mathrm{L}, 60 \mu \mathrm{g} / \mathrm{L}$ and $200 \mu \mathrm{g} / \mathrm{L}$ [43] and it has fresh, sweet, citrus notes [44]. (Z)-Furan linalool oxide was found to be most abundant terpene compound in T. caligatum and followed by drimenol and (E)-limonene oxide. Linalool is 
another important terpene compound which has refreshing, floral notes and it was only detected in $T$. caligatum. Odour threshold value of linalool is $15 \mu / \mathrm{L}$ [45], and it exceeded its threshold value. Drimenol was detected in both species; T. anatolicum and T. caligatum.

Ester group was another chemical class with one compound identified. Methyl cinnamate was determined both in T. anatolicum (30.2\%) and in T. caligatum (39.1\%). Methyl cinnamate is one of the major volatile compounds detected in Triholoma species. This cinnamic derivative compound has fruity-balsamic notes and it is also found to be a very important flavour compound [36, 37].

Among nine volatile acids detected in T. anatolicum, linoleic acid was the most abundant one and followed by hexadecanoic acid and oleic acid, respectively. This is in agreement with the results reported by Riberio et al. [46]. The volatile fatty acids (such as linoleic acid) are important compounds in mushroom, because they are the precursor to aliphatic compounds with eight carbons such as 1octen-3-ol, 2-octen-1-ol, 3-octanol, 1-octanol, 3-octanone which are the main compounds responsible for the characteristic mushroom-like odour $[12,36]$. In $T$. caligatum, only linoleic acid and hexadecanoic acid were detected. Normally, linoleic acid represents $63-74 \%$ of the fatty acids in mushrooms [36].

An Indole derivative compound; 2,5-dimethyl, 1-H- indole was the major component (41.5\%) found in T. caligatum and this compound was not detected in T. anatolicum. Indole derivatives of Tricholoma species were previously reported in a study performed by French scientists [37].

The results indicate that major volatile compositions of T. anatolicum and T. caligatum are significantly different. While 1-octen-3-ol was the most abundant volatile in T. anatolicum, indole derivative compound; 2,5-dimethyl,1-H-indole was the major compound in T. caligatum. Tricholoma anatolicum appears more similar to T. matsutake in terms of its volatile compounds. The phylogenetic analyses have also showed that they are very close each to other in a genetic manner. In a recent phylogenetic study, T. anatolicum has been nested in "Calicata" clade together with T. matsutake, T. magnivelare, T. caligatum, T. fulvocastaneum, T. ilkkae, T. dulciolens, T. bakamatsutake and T. anatolicum resolves as a sister of T. matsutake [47]. In fungi identification based on morphological features may sometimes be misleading due to the temporal changes in the phenotype with the effect of environmental conditions. Besides, the developmental stage of wild mushrooms is one of the important factors for morphotaxonomic identification, thus making sometimes identification of too undermature and overmature collections challenging. As to overcome misidentification issues, we used DNA sequencing technique to verify species identification, moreover when sequences of studied materials are deposited in public genetic databases, future reassessments of published chemical data, driven by taxonomic changes could be easily performed. In recent years, molecular systematic and chemical content studies have started to be evaluated together.

The characteristic aroma-active compounds of raw and cooked T. matsutake were investigated by aroma extract dilution analysis using gas chromatography-olfactometry [13]. 1-Octen-3-one (mushroom-like) found to be the major aroma-active compound was followed by ethyl 2methylbutyrate (floral and sweet), linalool (citrus-like), methional (boiled potato-like), 3-octanol (mushroom-like and buttery), 1-octen-3-ol (mushroom-like), (E)-2-octen-1-ol (mushroom-like), and 3octanone (mushroomlike and buttery) in the raw samples. Methional, 2-acetylthiazole (roasted), an unknown compound (chocolatelike), 3-hydroxy-2-butanone (buttery), phenylacetaldehyde (floral and sweet) and C8 compounds were detected as the major components in the cooked samples. Volatile profile of ectomycorrhizal mushroom species may be affected by host trees. T. matsutake tends to make ectomycorrhiza with $P$. densiflora. $P$. densiflora (red pine) is one of the common forest tree species in the Far East of Asia such as Korea, Japan and China [48, 49]. In a study carried out in Korea [48], volatile components of the needles of $P$. densiflora were identified by simultaneous distillationextraction using gas chromatography-mass spectrometry. At the end of the study; $\alpha$-pinene, $\beta$ phellandrene, germacrene $\mathrm{D}, \beta$-caryophyllene and myrcene were determined as major compounds. While (Z)-3-Hexenal (green/apple) and bornyl acetate (pine/herbaceous) were detected as important aroma-active compounds, $\alpha$-pinene (pine/fresh) was found to be the most intense aroma-active compound in the aroma extract dilution analyses. In another study performed again in Korea [49], volatile composition of needles of $P$. densiflora were determined by comparing six different extraction methods using gas chromatography-mass selective detector (GC-MSD). The researchers found 65 compounds classified into six categories: 25 hydrocarbons, 16 alcohols, 9 carbonyls, 6 esters, 7 acids and 2 ethers. The compounds having high or low boiling point showed different response in the six 
methods tested. In addition to; $\beta$-phellandrene, $\beta$-myrcene, $\alpha$-pinene, $\beta$-pinene and limonene were detected as major compounds similar to the previous study [48]. Tricholoma anatolicum is linked toprefers $C$. libani in ectomycorrhizal relationship. Volatile composition of $C$. libani from the ancient Lebanese forests were identified and compared with the ones grown in Jerusalem using GC/MS [50]. While $\alpha$-pinene, $\beta$-pinene, myrcene and limonene were detected as major aroma compounds in the needles of $C$. libani, sesquiterpens $\alpha$ - and $\beta$-himachalene were determined in the wood. Manool, atlantones, $\beta$-himachalene oxide and longiborneol were identified to be main oxygenated components of Lebanese Cedar wood extract. Chemical characterization of $C$. libani tar obtained by the traditional method and Jenkner Retort was carried out in roots and fallen branches using FID-GC and GC-MS [51]. The tar yield was found to be $60 \%$ and $30-40 \%$ in the Jenkner Retort and traditional method, respectively. Totally, 41 compounds were detected and $\beta$-himachalane, $\alpha$-himachalane and longifolene were assessed as the main components in the all tars. Some compounds known with antifungal and insecticidal effects such as deodarone and E- $(\alpha)$-atlantone were just recorded in tars of roots.

Volatile studies on different Tricholoma species such as T. equestre, T. ustaloides, $T$. sulphureum and T. terreum have been carried out by different researchers. Volatile and semi volatile components of eleven wild edible mushroom species including T. equestre collected under $P$. pinaster were detected by using HS-SPME and GC-MS [15]. The eleven mushroom species were evaluated in three groups and $T$. equestre was nested in the second group described as "hay-herb, nutty and mushroom like" and found to be rich in 1-octen-3-ol and 3-octanol. Volatile aroma composition of $T$. terreum collected from Turkey was determined by using HS-SPME/GC-MS [17]. 1-octen-3-ol (37.08\%), (E)-2-octen-1-ol (19.68\%), hexanal (16.00\%), 3-octanone (3.36\%), acetic acid (2.63\%) and (E)-2-octenal (2.27\%) were found to be major aroma compounds among 17 components obtained. Volatile organic compounds (VOS) of seven wild inedible macrofungi species including T. ustaloides and T. sulphureum collected from the Mediterranean Basin were investigated by using HS-SPME and GC-MS [16]. Totally 72 different compounds including 5 esters, 17 alcohols, 14 aldehydes, 9 ketones, 18 terpenes and 9 other compounds were identified. With 28 compounds, the maximum number of VOCs was determined in $T$. sulphureum. In terms of C8 derivatives such as 3-octanol, 3-octanone, 1octen-3-ol, trans-2-octenal and 1-octen 3-one, T. sulphureum was found to be rich together with Hygrophorus cossus, Mycena pura and Clitocybe odora. Especially, 1-octen-3-ol was recorded to have highest amount in T. sulphureum with $81.2 \%$. The studies carried out in Tricholoma species have clearly shown that C8 components have been found most species belonging to the genus Tricholoma at different quantity. The number and amount of $\mathrm{C} 8$ derivatives were high in T. anatolium as in most other species of the genus Tricholoma. However, most C8 compounds could not be detected in $T$. caligatum. Although this result seems surprising at first glance, similar data were obtained in the study conducted by the French group [37]. However, as it was already mentioned above, aroma composition of mushrooms is influenced by different factors such as environment, the stage of maturity and part of the mushroom fruitbodies used. Unlike mushrooms that cannot be cultured, it is easier to optimize such factors in mushroom species, obtained in culture. In mushrooms that cannot be cultured, it may be difficult to find collections in the same stage and maturity for study. For all these reasons, aromatic studies on T. caligatum should be continued by analyzing samples from different localities and at different stages of maturity.

\section{Conclusions}

In mushrooms species identification by macromorphological and microscopic diagnostic methods may be sometimes challenging due to variety of intrinsic and extrinsic factors. Therefore, molecular methods, especially based on DNA sequencing, are able to aid the process significantly. Despite all these difficulties in species identification, some mushroom species can be recognized due to their typical odour, morphology and ecology. Many collectors or researchers claim that $T$. anatolicum can easily be separated from other Tricholoma species by its odour. The results of this research clearly show that $T$. anatolicum is rich in terms of aroma components which are important for mushroom flavor such as 1-octen-3-ol, 3-octanol, 3-octanone and 1-octen 3-one. All these important ingredients strengthen the odour of this species. Among Tricholoma species, the food quality of $T$. matsutake is considered high because of its intense flavor, glance, which is appreciated by consumers. For this reason, this species is sold at high prices and it is highly valued, especially on the Japanese 
market. The present study revealed that $T$. anatolicum shows aromatic profile similar to T. matsutake, supplemented by tar odour apparently derived from its mycorrhizal host tree C. libani.

\section{Acknowledgments}

The authors would like to express their thanks to Mr Şaban Güneri (Republic of Turkey Ministry of Forest and Water Resources) for his aid in collecting mushroom samples, and to the Cukurova University, Scientific Research Projects Coordinating Office for supporting financially this study though grant FYL-2018-10495.

\section{ORCID}

Hatıra Taşkın: 0000-0002-1784-4731

Zeynep Dilan Çelik: 0000-0003-1328-8106

Fuat Bozok: 0000-0002-9370-7712

Turgut Cabaroğlu: 0000-0003-1489-9929

Saadet Büyükalaca: $\underline{0000-0002-1129-2729}$

\section{References}

[1] M. Intini, H. H. Doğan and R. Alfredo (2003). Tricholoma anatolicum spec. nov.: a new member of the matsutake group, Micolog. Vegetaz. Mediterr. 18, 135-142.

[2] H.H. Doğan and I. Akata (2011). Ecological features of Tricholoma anatolicum in Turkey, Afr. J. Biotechnol. 10, 12626-12668.

[3] K. Savaş (1946). Antalya işletmesi ormanlarında bazı notlar ve Karadeniz ardı mıntıkasında sedir meşcereleri. Akın Matbaası, Ankara.

[4] M. Sevim (1952). Lübnan sedirinin (Cedrus libani Barr.) Türkiye'deki tabii yayılışı ve ekolojik şartları, I. Ü. Orman Fak. Derg. 2, 19-46.

[5] M. Y. Akıncı (1963). Doğu Karadeniz mıntıkası sedir (Cedrus libani) meşcereleri, İ.̈̈. Orman Fak. Derg. 13, 103-113.

[6] M. D. Kantarcı (1982). Türkiye sedirleri (Cedrus libani A. Rich.) ve doğal yayılış alanında bazı ekolojik ilişkiler, İ.Ü. Orman Fak. Derg. 32, 113-198.

[7] M. D. Kantarc1 (1982b). Ökologische Verhältnisse im natürlichen verbreitungsgebiet der zeder (Cedrus libani A. Richard) in der Türkei. IUFRO-Gruppe URWALD-Symposium in Wien, pp. 164-182.

[8] F. Yaltırık (1993). Dendroloji Ders Kitabı I Gymnospermae (Açık Tohumlular), Istanbul University Publication, İstanbul.

[9] Y. Karatepe, H. Süel and İ. Yetüt (2005). Isparta Gölcük Tabiat Parkı'nda toros sediri (Cedrus libani A. Rich.)'nin farklı anakayalardan oluşmuş topraklardaki gelişiminin ekolojik irdelenmesi, SDÜ Orman Fak. Derg. 1, 64-75.

[10] C. Duran, H. Taşkın and S. Büyükalaca (2011). Determination of ecological requirements of cedar mushroom (Tricholoma anatolicum Doğan \& Intini) in Feke-Adana, Alatarım 10, 42-49.

[11] H. Taşkın and S. Büyükalaca (2017). Minimally Processed Mushrooms, In: Minimally Processed Refrigerated Fruits and Vegetables, ed: F. Yildiz, R.C. Wiley, Springer Nature, MA, USA, pp. 433468.

[12] R. Malheiro, P. G. Pinho, S. Soares, A. C. S. Ferreira and P. Bapista (2013). Volatile biomarkers for wild mushrooms species discrimination, Food Res. Int. 54, 186-194.

[13] I. H. Cho, S. M. Lee, S. Y. Kim, H. K Choi, K. O. Kim and Y. S. Kim (2006). Characterization of aroma-active compounds in raw and cooked pine-mushrooms (Tricholoma matsutake Sing.), J. Agr. Food. Chem. 54, 6332-6335.

[14] I. H. Cho, S. M. Lee, S. Y. Kim, H. K Choi, K. O. Kim and Y. S. Kim (2007). Differentiation of aroma characteristics of pine-mushrooms (Tricholoma matsutake Sing.) of different grades using gas chromatography-olfactometry and sensory analysis, J. Agr. Food. Chem. 55, 2323-2328.

[15] D. G. Pinho, B. Ribeiro, R. F. Gonçalves, P. Baptista, P. Valentao, R. M. Seabra and P. B. Andrade (2008). Correlation between the pattern volatiles and the overall aroma of wild edible mushrooms, $J$. Agr. Food Chem. 56, 1704-1712.

[16] E. Palazzolo, F. Saiano, V. A. Laudicina, M. L. Gargano and G. Venturella (2017). Volatile organic compounds in wild fungi from Mediterranean forest ecosystems, J. Essent. Oil Res. 29, 385-390.

[17] F. Bozok, H. H. Dogan, H. Taskin, E. Kafkas and S. Büyükalaca (2017). Volatile constituents of the edible Tricholoma terreum in Marmara region of Turkey, J. Essent. Oil. Bear. Pl. 20, 253-258. 
[18] E. Kalmış, H. Yıldız, B. Ergönül, F. Kalyoncu and M. H. Solak (2011). Chemical composition and nutritional value of a wild edible ectomycorrhizal mushroom, Tricholoma anatolicum, Turk. J. Biol. 35, 627-633.

[19] H. H. Doğan, M. A. Şanda and I. Akata (2012). Mn, Fe, K, Na, and P contents in some Tricholoma (Fr.) Staude (Tricholomataceae) taxa from central Anatolia, Turkey, Fresen. Environ. Bull. 21, 3389-3393.

[20] S. Selli, A. Canbaş, T. Cabaroğlu, H. Erten and Z. Günata (2006). Aroma components of cv. Muscat of Bornova wines and influence of skin contact treatment, Food Chem. 94, 319-326.

[21] Z. D. Çelik, T. Cabaroğlu and S. Krieger-Weber (2018). Impact of malolactic fermentation on the volatile composition of Turkish Kalecik karas1 red wines, J. Inst. Brew. doi 10.1002/jib.540.

[22] T. J. White, T. Bruns, S. Lee and J. W. Taylor (1990). Amplification and direct sequencing of fungal ribosomal RNA genes for phylogenetics, In: PCR protocols: a guide to methods and applications, ed. M. A. Innis, D. H. Gelfand, J. J. Sninsky, T. J. White, Academic Press, San Diego, USA, pp. 315-322.

[23] A. S. Sönmezdağ, H. Kelebek and S. Selli (2018). Pistachio oil (Pistacia vera L. cv. Uzun): Characterization of key odorants in a representative aromatic extract by GC-MS-olfactometry and phenolic profile by LC-ESI-MS/MS, Food Chem. 240, 24-31.

[24] D. B. Cho, H. Y. Seo and K. S. Kim (2003). Analysis of the volatile compounds produced during the growth stages of the Shiitake Mushrooms (Lentinus edodes), Prevent. Nutr. Food Sci. 8, 306-314.

[25] I. H. Cho, H. K. Choi and Y. S. Kim (2006). Difference in the volatile composition of pine-muchrooms (Trciholoma matsutake Sing.) according to their grades, J. Agric. Food Chem. 54, 4820-4825.

[26] S. J. Lee, K. Umano, T. Shibamoto and K. G. Lee (2005). Identification of volatile compponents in basil (Ocimum basilicum L.) and thyme leaves (Thymus vulgaris L.) and their antioxidant properties, Food Chem. 91, 131-137.

[27] I. H. Cho, H. J. Namgung, H. K. Choi and Y. S. Kim (2008). Volatiles and key odorants in the pileus and stipe of pine-mushroom (Tricholoma matsutake Sing.), Food Chem. 106, 71-76.

[28] N. T. L. Phi, C. Nishiyama, H. S. Choi and M. Sawamura (2006). Evaluation of characteristic aroma compounds of Citrus natsudaidai Hayata (Natsudaidai) cold-pressed peal oil, Biosci. Biotechnol. Biochem. 70, 1832-1838.

[29] M. Beret, P. Brat, C. Mertz, M. Lebrun and Z. Günata (2011). Contribution to aroma potential of Andean blackberry (Rubus glaucus Benth.), Food Res. Int. 44, 54-60.

[30] E. Cantergiani, H. Brevard, Y. Krebs, A. Feria-Morales, R. Amadò and C. Yeretzian (2001). Characterization of the aroma of green Mexican coffee and identification of mouldy/earthy defect, Eur. Food Res. Technol. 212, 648-657.

[31] A. Amanpour, G. Güçlü, H. Kelebek and S. Selli (2019). Characterization of key aroma compounds in fresh and roasted terebinth fruits using aromaextract dilution analysis and GC-MS-Olfactometry, Microchem. J. 145, 96-104.

[32] C. C. Chyau, P. T. Ko, C. H. Chang, and J. L. Mau (2003). Free and glycosidically bound aroma compounds in lychee (Litchi chinensis Sonn.), Food Chem. 80, 387-392.

[33] H. Shiratsuchi, M. Shimoda, K. Imayoshi, K. Noda and Y. Osajima (1994). Volatile flavor compounds in spray-dried skim milk powder, J. Agric. Food Chem. 42, 984-988.

[34] Q. Li, L. Zhang, W. Li, X. Li, W. Huang, H. Yang and L. Zheng (2016). Chemical compositions and volatile compounds of Tricholoma matsutake from different geographical areas at different stages of maturity, Food Sci. Biotechnol. 25, 71-77.

[35] X. Ding and Y. L., Hou (2012). Identification of genetic characterization and volatile compounds of Tricholoma matsutake from different geographical origins, Biochem. Syst. Ecol. 44, 233-239.

[36] I. Yajima, T. Yanai, M. Nakamura, H. Sakakikibara and K. Hayashi (1981). Volatile flavour compounds of Matsutake-Tricholoma matsutake (Ito et Imai) Sing, Agr. Biol. Chem. 45, 373-377.

[37] F. Fons, S. Rapior, S. A. Fruchier, P. Saviuc and J. M. Bessière (2006). Volatile composition of Clitocybe amoenolens, Tricholoma caligatum and Hebeloma radicosum, Cryptogam. Mycol. 27, 45-55.

[38] S. Assaf, Y. Hadar and C. G. Dosoretz (1995). Biosynthesis of 13-hydroxyperoxylinoleate, 10- oxo-8decanoic acid, and 1-octen-3-ol from linoleic acid by a mycelial- pellet homogenate of Pleruotus pulmonarius, J. Agric. Food Chem. 43, 2173-2178.

[39] K. Matsui, S. Sasahara, Y. Akakabe, T. Kajiwara (2003). Linoleic acid 10-hydroxyperoxide as an intermediate during formation of 1-octen-3-ol from linoleic acid in Lentinus decadetes, Biosci. Biotechnol. Biochem. 67, 2280-2282.

[40] A. J. Maga (1981). Mushroom flavor, J Agr. Food Chem. 29, 1-4.

[41] E. Combet, J. Henderson, D. C. Eastwood and K. S. Burton (2006). Eight-carbon volatiles in mushrooms and fungi: properties, analysis and biosynthesis, Mycoscience 47, 317-326.

[42] P. K. Ouzouni, W. D. Koller, A. V. Badeka and K. A. Riganakos (2009). Volatile compounds from the fruiting bodies of three Hygrophorus mushroom species from Northern Greece, Int. J. Food Sci. Tech. 44, 854-859. 
[43] A. Plotto, C. A. Margaría, K. L. Goodner, R. Goodrich and E. A. Baldwin (2004). Odour and flavour threholds for key aroma components in an orange juice matrix: terpenes and aldehydes, Flavour Frag. J. 19, 491-498.

[44] S. Breheret, T. Talou, S. Rapior, and J. M. Bessière (1997). Monoterpenes in the aromas of fresh wild mushrooms (Basidiomycetes), J. Agric. Food Chem. 45, 831-836

[45] R. Lòpez, N. Ortin, J. P. Pérez-Trujillo, J. Cacho and V. Ferreira (2003). Impact odorants of different young white wines from the Canary Island, J. Agric. Food Chem. 51, 3419-3425.

[46] B. Riberio, P. G. Pinho, P. B. Andrade, P. Baptista and P. Valenão (2009). Fatty acid composition of wild edible mushroom species: A comparative study, Microchem. J. 93, 29-35.

[47] J. Heilmann-Clause, M. Christensen, T. G. Frøslev and R. Kjøller (2017). Taxonomy of Tricholoma in northern Europe based on ITS sequence data and morphological characters, Persoonia 38, 38-57.

[48] E. J. Yu, T. H. Kim, K. H. Kim and H. J. Lee (2004). Aroma-active compounds of Pinus densiflora (red pine) needles, Flavour Frag. J. 19, 532-537.

[49] J. G. Lee, C. G. Lee, S. Baek, Y. J. Kwon, J. J. Jang Kwag, M. S. Rhee and G. H. Lee (2006). Determination of aroma components in Pinus densiflora (Pine Needles) studied by using different extraction methods, Korean J. Food Nutr. 19, 161-168.

[50] A. Fleisher and Z. Fleisher (2000). The volatiles of the leaves and wood of Lebanon Cedar (Cedrus libani A. Rich) Aromatic plants of Holy Land and Sinai. Part XIV, J. Essent. Oil Res. 12,763-765.

[51] A. K. Pekgözlü, S. Kuştaş, B. Mercan and A. Biçer (2017). Chemical characterization of Lebanon cedar Tar., Drvna Industr. 68, 107-112.

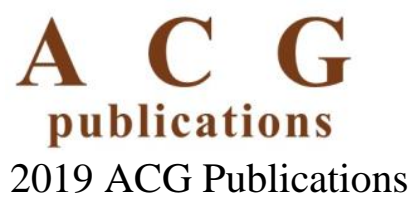

